\title{
REVISTAMARACANAN
}

Nota de Pesquisa

\section{Estratégias sociais nas festas de São Sebastião: o exemplo do arrematador José Antônio de Freitas Guimarães no Rio de Janeiro (1795-1810)*}

\section{Social stratagies in the São Sebations festivities: the exemple of the bidder José Antonio de Freitas Guimarães in Rio de Janeiro (1795-1810)}

\author{
Maria Beatriz Gomes Bellens Porto ${ }^{* *}$ \\ Universidade Federal do Rio de Janeiro \\ Faculdade de Belford Roxo \\ mbporto@gmail.com
}

\begin{abstract}
Resumo: A presente pesquisa tem como objetivo abordar as estratégias de parte da elite do Rio de Janeiro colonial ao buscar na administração pública, e na religiosidade, caminhos para se manter na hierarquia social da cultura política da sociedade de Antigo Regime. Um desses lugares era o Senado da Câmara do Rio de Janeiro, que ao administrar a festa de São Sebastião e seu oitavário (oito dias de festa), utilizava um sistema de arrematação no qual indivíduos forneciam os itens necessários para a celebração e depois cobravam exatamente o seu valor para os camarários, na busca por honra e prestígio, sendo José Antônio de Freitas Guimarães o mais regular e maior arrematador entre os anos de 1795 a 1810 .
\end{abstract}

Palavras-chave: Rio de Janeiro. Senado da Câmara. Festa de São Sebastião; Arrematação.

\begin{abstract}
The present research has the purpose of approaching the strategies of part the elite in colonial Rio de Janeiro, as they sought ways to maintain their places in the social hierarchy of the Old Regime city, through the public administration and religiosity. One of those places was the City Council of Rio de Janeiro, which used to organize Saint Sebastian's Feast Day and its Octave (eight consecutive days of celebration), and used a system of public auctions where individuals would supply the city with the necessary items for the celebrations and then charge the Council at cost, in pursuit of honor and prestige. José Antônio de Freitas was the most frequent bidder from 1795 to 1810.
\end{abstract}

Keywords: Rio de Janeiro. City Council. Saint Sebastian's Feast. Public Auctions.

Recebido: 12 abr. 2018.

Aprovado: 11 jun. 2018.

\footnotetext{
* A presente pesquisa é financiada pela Coordenação de Aperfeiçoamento de Pessoal de Nível Superior CAPES.

** Doutoranda em História Social pelo Programa de Pós-graduação em História Social da Universidade Federal do Rio de Janeiro (UFRJ) e Professora dos cursos de Licenciatura em História e Pedagogia da Faculdade de Belford Roxo (FABEL). Possui mestrado em História Moderna pela Universidade Federal Fluminense; bacharelado e licenciatura em História pela UFRJ.
} 
Frequentemente estudadas, as Câmaras municipais são espaços que perpassam questões como poder, honra e prestígio, fosse na ocupação dos cargos políticos, ou através da análise de grandes contratos, como das carnes, talhos e demais produtos coloniais e até mesmo nos estudos sobre as festas oficiais. E é justamente em um outro olhar sobre tais festas que reside nossa análise, que pretende entender como se dava a realização das mesmas, através de um grupo social ainda pouco estudado dos arrematadores das festas oficiais, homens e mulheres que forneciam os principais itens para a realização das celebrações e depois cobravam o seu exato valor ao Senado da Câmara. Aqui o recorte se dá pelas festas ao padroeiro do Rio de Janeiro, São Sebastião, e pelo maior fornecedor no final dos séculos XVIII-XIX, o capitão e homem de negócios José Antônio de Freitas Guimarães.

Em estudo clássico, Pierre Bourdieu definiu que mesmo no entendimento da sociedade onde tudo é visto como poder, ainda há alguns pontos onde este é menos visto, sendo quase ignorado, e é neste momento que o "poder simbólico é o poder invisível no qual só pode ser exercido com a cumplicidade daqueles que não querem saber que lhe estão sujeitos ou mesmo que os exercem". ${ }^{1}$ Assim, os arrematadores da festa de São Sebastião se colocavam como atuantes do sistema simbólico que estrutura a sociedade de Antigo Regime, como uma das estratégias sociais encontradas pelo poder local do ultramar. Assim, ao tratar de uma sociedade marcada pelo simbolismo religioso e político, as insígnias, trajes, rezas, procissões, armações, palio, cera e andor se colocam na interseção entre monarquia e religião.

\section{O Senado da Câmara do Rio de Janeiro}

As Câmaras municipais do Império português administravam e realizavam festas oficiais reais em homenagem a nascimentos, casamentos, óbitos e eventos extraordinários ligados à monarquia portuguesa, além das festas oficiais religiosas, tais como a do Corpo de Deus (entre maio e junho, celebrando os triunfos de Portugal) considerada a procissão das procissões, presente em toda a América Portuguesa como elemento unificador do Reino. ${ }^{2}$ Além disso, os festejos a São Sebastião (20 de janeiro, por ser defensor da Igreja), pela Visitação de Nossa Senhora à Santa Isabel ( 2 de julho), ao Anjo Custódio ( $3^{\circ}$ domingo de julho) e partir de 1758 para São Francisco de Borja (10 de outubro), instituído como protetor do Reino e domínios ultramarinos contra terremotos, três anos depois da destruição de Lisboa. ${ }^{3}$

Frequentemente apontadas pela historiografia como um espaço de unidade $\mathrm{e}$ continuidade, as Câmaras municipais não podem ser vistas apenas como o elo entre

\footnotetext{
${ }^{1}$ BOURDIEU, Pierre. O poder simbólico. Lisboa: Difel, 1989, p. 8, 9.

2 SANTOS, Beatriz Catão Cruz. O Corpo de Deus na América: a festa de Corpus Christi nas cidades da América portuguesa-século XVIII. São Paulo: Annablume, 2005.

${ }^{3}$ Arquivo Histórico Ultramarino (AHU). Atas do Conselho de Lisboa (ACL), CU 017, cx. 52, doc. 5236. Rio de Janeiro, 23 jul. 1757.
} 
governadores, bispos e demais oficiais, ou seja, entre colônias e coroa. ${ }^{4}$ Se a instituição estava espalhada pela América, África, Ásia de domínio português, suas demandas por mais que se assemelhassem às do Reino, atendiam às questões locais, não como uma simples transposição de deveres e direitos, mas como espaço de administração, política e economia. Os estatutos das Câmaras mudavam de acordo com sua importância e abrangência. Maria de Fátima Gouvêa aponta que a Câmara do Rio de Janeiro passou por um progressivo acúmulo de prestígio político e autonomia fiscal quando a praça fluminense se torna a mais importante do centro sul, após exploração das Gerais e sua comunicação com a Colônia de Sacramento, ${ }^{5}$ no que Maria Fernanda Bicalho definiu como "o tripé Rio de Janeiro-Minas-Colônia do Sacramento, que viria se somar, em novos moldes - e com uma importância geopolítica jamais vivida por aquela capitania anteriormente". ${ }^{6}$

Na América portuguesa, as despesas dos Senados da Câmara giravam em torno das questões municipais como obras e edificações públicas, saneamento básico, custos com a defesa - como o fardamento, sustento e pagamento de soldos das tropas e guarnições, construção e reparo das fortalezas, arcando com o custeio de naus guarda-costas contra piratas e corsários, e mantendo armadas para situações excepcionais, afora, claro, a realização das festas. ${ }^{7}$

Já os rendimentos advinham do abastecimento de víveres à população, com as taxas para o arrendamento dos contratos, estabelecimento de preços, impostos para as condições de venda, medidas e qualidade dos produtos coloniais no abastecimento da sociedade por meio da almotaçaria, que também aplicavam as condenações ou coimas (por não cumprimento de posturas da Câmara). Além disso, dos pagamentos de impostos sobre os foros, por imposição de taxas permanentes ou ocasionais tanto por ordens reinóis ou criadas pela própria Câmara. ${ }^{8}$ Bicalho explica que as Câmaras eram um poder alargado das municipalidades, e seus membros, os homens bons, assumiam os altos custos de manutenção do Império. ${ }^{9}$

O sistema de arrematação dos contratos era uma tradicional maneira de cobrança de impostos na sociedade portuguesa de Antigo Regime, explicitada pela dificuldade da Coroa em administrar as arrecadações e também na possibilidade de se adiantar recursos por meio dos pregões públicos. Em geral, os arrendamentos significavam fixar preços e fornecer os

\footnotetext{
${ }^{4}$ BICALHO, Maria Fernanda. As Câmaras Municipais no Império Português: O Exemplo do Rio de Janeiro. Revista Brasileira História, São Paulo, v. 18, n. 36, 1998.

${ }^{5}$ GOUVÊA, Maria de Fátima. O Senado da Câmara e a transferência da família Real portuguesa para o Brasil: perspectivas de estudos e um índice temático de fontes do Arquivo Geral da Cidade do Rio de Janeiro, 1786-1822. Rio de Janeiro: Secretaria Municipal de Cultura; AGCRJ, 2012, p. 30.

${ }^{6}$ BICALHO, Maria Fernanda. As Câmaras Municipais no... Op. cit.

7 AHU. ACL, CU 17-01, cx. 4, doc. 624. 16 out. 1647; BICALHO, Maria Fernanda. As Câmaras Ultramarinas e o governo do Império. In: FRAGOSO, João; BICALHO, Maria Fernanda; GOUVÊA, Maria de Fátima (orgs.). O Antigo Regime nos trópicos: dinâmica imperial portuguesa (séculos XVI-XVIII). Rio de Janeiro: Civilização Brasileira, 2001, p. 199.

8 BICALHO, Maria Fernanda. A cidade e o Império: O Rio de Janeiro no século XVIII. Rio de Janeiro: Civilização Brasileira, 2003, p. 305. Cf.: MONTEIRO, Nuno Gonçalo. Os Concelhos e as Comunidades. In: MATTOSO, José. (dir.). História de Portugal. Vol. 4: O Antigo Regime, 1620-1807. Org.: Antônio Manuel Hespanha. Lisboa: Estampa, 1998.

${ }^{9}$ BICALHO, Maria Fernanda. A cidade e o Império... Op. cit., p. 305.
} 
produtos, ou seja, garantir o abastecimento da cidade, sendo os principais itens a carne, o trigo, e sal.

Garantir o abastecimento desses itens se constituiu em estratégia de manutenção da ordem social na cidade. Daí a importância da forma como os oficiais da Câmara atuaram no sentido de fixar periodicamente o preço dos produtos, bem como em providenciar o arrendamento de contratos e o fornecimento dos produtos de modo satisfatório. ${ }^{10}$

No Rio de Janeiro, as arrematações se davam no paço do Senado da Câmara, ${ }^{11}$ após os oficiais e o Juiz de Fora, presidente do Senado, registrarem em ato de vereanças quais eram as arrematações dos bens do Concelho. A seguir, era lançada em pregão público pela representação do porteiro e quem desse o maior lance ganhava o direito do monopólio da comercialização do produto em determinada região por até três anos. ${ }^{12}$

No entanto, no que diz respeito às festas, o funcionamento se dava de uma maneira um tanto distinta. Arrematados anos a ano, quem desse o menor lance garantia o direito ao fornecimento de itens necessários para as procissões religiosas e oficiais. Além disso, o valor do lance público era muito mais volátil que o de carnes, variando especialmente pelo tipo de produto, sendo o valor da cera de vela o mais variante a cada festividade. No "auto de arrematação da cera que fez Manuel Álvares Machado para as festas do Senado, tanto as ordinárias quanto as extraordinárias", o fornecedor recebeu em 12 de maio de 1798 a quantia de 350 réis para cada libra da cera, dois anos antes, ele mesmo arremataria por 550\$ cada libra e em 1801, Manuel Pinho Correia receberia o valor de $465 \$$ por cada libra. ${ }^{13}$ A documentação explicita que Manuel Álvares Machado tinha a obrigação de "dar toda a quantia que se precisasse para as referidas festas tanto ordinárias como extraordinárias e por não dever quem por menor o fizesse [o lance] mandaram ao dito o que ele assim o fez dizendo em voz alta as palavras". ${ }^{14}$

Assim, tratava-se de um item que não seria comercializado a posteriori, mas abastecido para a realização das festas e quem arrematasse tinha a obrigação de dar toda a quantia e qualidade que o Senado indicasse. ${ }^{15}$ No entanto, o bem fornecido era cobrado depois ao Senado da Câmara no seu valor total e sem nenhum adicional, numa solicitação clara e direta: "porque quer haver o seu pagamento". ${ }^{16}$ Ganhava-se o direito de administrar a festa junto do Senado da Câmara, adiantar os emolumentos necessários para o que era um dos maiores gastos desta instituição, como uma espécie de sistema de crédito. Ao todo a pesquisa, que se

${ }^{10}$ GOUVÊA, Maria de Fátima. O Senado da Câmara... Op. cit., p. 30.

${ }^{11}$ CAVALCANTI, Nireu. O Rio de Janeiro setecentista. Rio de Janeiro: Zahar, 2004, p. 355.

12 Segundo Avanete Sousa, o pregão durava em média um mês, quando eram apurados os lances finais e buscava-se a elevação dos preços, com a intervenção do porteiro da Câmara, como observado neste documento. SOUSA, Avanete Pereira. Poder Local, cidades e atividades econômicas (Bahia, século XVIII). 2003. Tese (Doutorado em História) - Universidade Federal de São Paulo, São Paulo, p. 209.

${ }_{13}$ Arquivo Geral da Cidade do Rio de Janeiro (AGCRJ). 43.4.18, Festividades de São Sebastião 17861830 , p. $56 ; 63$ A.

${ }_{14}$ AGCRJ. 39.3.51, Arrematações Senado da Câmara 1795-1806, p.50.

${ }^{15}$ Idem.

${ }^{16}$ AGCRJ. 43.4.18, Festividades de São Sebastião 1786-1830. 
está em andamento, conta com 31 indivíduos, sendo que 3 desses eram mulheres, que estavam atrelados a administração das festas de São Sebastião entre 1790 a 1828.

Importante destacar que na presente análise o termo arrematador é usado para se referir a pessoas da sociedade civil que não eram funcionários da Câmara, nem necessariamente pertenciam alguma irmandade, ou a grupos sociais pertencentes as instituição seculares e regulares que realizavam as festas oficiais, ${ }^{17}$ são indivíduos que se consideram aptos à concorrer aos editais de arrematação publicados pela Câmara para as festas oficiais da monarquia portuguesa no Rio de Janeiro, sendo esse movimento uma das atividades que eles realizavam, por muitos serem militares e ou negociantes de grosso trato, comerciantes, dentre outros, e são considerados elites justamente por terem a possibilidade de empregar montantes em réis e aguardar o pagamento meses após as festas.

\title{
A festa de São Sebastião
}

Roger Chartier explica que os atores sociais criam práticas e discursos em torno de suas atitudes, como se posicionam na sociedade, como se vestem, que rituais participam e demonstra como toda as suas concepções servem para que suas esferas culturais atuem sobre o social, justamente pelas representações do mundo social que se constrói. ${ }^{18} \mathrm{~A}$ complexidade do tecido social e cultural que determinam essa representação é de fundamental importância para não desvincularmos os interesses dos grupos sociais. As festas coloniais se caracterizavam pelos desfiles de símbolos, danças, máscaras, rezas e luzes, era o mundo em sua plena representação.

A festa colonial permitiu a "universalização da missão catequética" e foi um dos meios encontrados para o poder local enraizar suas estruturas na América Portuguesa, onde o Senado da Câmara, bispados, ordens religiosas e misericórdias e a população em geral participavam de cortejos e procissões e

\begin{abstract}
Inseridas na lógica da cultura política do Antigo Regime, as pessoas recebiam, davam e retribuíam nas ocasiões festivas, pondo em circulação solidariedades, mercadorias, os costumes e as regras que orientavam a vida social. Seja no financiamento das armações efêmeras, da iluminação pública, dos fogos de artifícios, e dos divertimentos públicos, ou mesmo, mediante a prática da etiqueta ou a exibição da pompa, a festa luso-brasileira procurava impor uma ordenação forma a um mundo aparentemente instável ${ }^{19}$
\end{abstract}

Beatriz Catão Cruz Santos ao analisar sobre as cerimônias religiosas, enfocando no Corpo de Deus na América portuguesa do século XVIII, aponta para uma monarquia com

\footnotetext{
17 A exceção do fornecimento da música das festividades, que sempre era arrematado pelo mestre capelão da Sé.

18 CHARTIER. Roger. A História Cultural: entre práticas e representações. Portugal: Diefel, 1988, p.17, passim.

19 KANTOR, Iris; JANCSÓ, István, Falando de festa. In: KANTOR, Iris; JANCSÓ, István (orgs.) Festa: Cultura e sociabilidade na América portuguesa. Vol. I. São Paulo: Hucitec; EdUSP; FAPESP; Imprensa Oficial, 2001, p. 11.
} 
vocação apostólica, ou seja, quando a religião parece conferir sentido à comunidade política. ${ }^{20}$ Assim, ao entender política e religiosidade num caráter indissociável, Santos também nos aponta para outro aspecto norteador da pesquisa, como o Senado da Câmara era responsável pela organização e condução das procissões religiosas que administrava

\begin{abstract}
Há de se destacar o papel da Câmara, que regulamenta a festa e considera, em prática a ordem régia. Assim como das diversas funções que a Câmara possuía com relação à festa tanto do Reino, quanto na América Portuguesa. Para definir a importância e variedade de funções da Câmara, que incluía, por exemplo, o anúncio público da festa, indicar o acompanhamento, nomear quem seguraria as varas do palio, considerei que era a Câmara responsável pelo enquadramento espaço-temporal da procissão do Corpo de Deus ${ }^{21}$
\end{abstract}

Ainda sobre a lógica da cultura política, Ronald Raminelli expõe que em geral ordens religiosas ou irmandades organizavam e financiavam os festejos coloniais, "mas que as Câmaras que se destacavam como patrocinadores de cerimonias religiosas e públicas"22 e que eventualmente particulares patrocinavam festas, como o caso do famoso "Triunfo Eucarístico" ocorrido em 1733 em Vila Rica, financiado por um magnata anônimo, natural e morador de Lisboa. O que se observa para o Rio de Janeiro é uma junção dos dois modos, o financiamento de particulares, vários e de forma recorrente, e da Câmara, por meio do pagamento do ressarcimento do que era gasto.

A devoção a São Sebastião na cidade que receberia seu nome surge por alguns vieses, como homenagem ao rei Dom Sebastião, nascido em 20 de janeiro de 1554, e pelo próprio santo, soldado pretoriano perseguido pelo Imperador Diocleciano e morto por volta do ano de 288, após sobreviver as seteadas pela qual sua iconografia é conhecia. Além disso, a homenagem ao santo se dava pela crença de que o Glorioso Mártir teria sido visto lutando lado a lado dos portugueses e índios na defesa da cidade do Rio de Janeiro, na famosa batalha de Uruçumirim contra os franceses, ocorrida também no dia do santo, em 20 de janeiro de 1567..$^{23}$

Vieira Fazenda explica que em 1734 a maior celebração da festa de São Sebastião, a procissão, passou a ser realizada dia 27 de janeiro, começando por uma missa de consagração no dia do santo, dia $20,{ }^{24}$ tendo solenidades em todos oito dias, os oitavários. O motivo seria comportar melhor a população nas comemorações do padroeiro e não sobrecarregar as pequenas ruas do Morro do Castelo, onde ficava a Sé Velha. Anualmente, a Sé publicava um edital entre os dias 14 a 19 de janeiro, autorizando "a procissão solene do Glorioso Mártir São Sebastião saindo da Santa Igreja Catedral e pelas Ruas do Rosário até o canto da rua de trás da Candelária voltando pela esquerda até as dos Pescadores e seguindo a Rua Direita

\footnotetext{
20 SANTOS, Beatriz Catão Cruz. O Corpo de Deus... Op. cit., p. 54.

${ }^{21}$ Ibidem, p. 53.

22 RAMINELLI, Ronald. Festas. (Verbete). In: VAINFAS, Ronaldo (dir.). Dicionário do Brasil colonial (15001808). Rio de Janeiro: Objetiva, 2000, p. 233.

23 HOLANDA, Sérgio Buarque de. Visão do Paraíso. Os motivos endêmicos no descobrimento e colonização do Brazil. São Paulo: Brasiliense, 1994, p. 161.

${ }^{24}$ Vieira Fazenda, Antiqualhas e memórias do Rio de Janeiro. Revista do Instituto Histórico e Geográfico Brasileiro, t. 86, v. 140, 1919, p. 144.
} 
continuarão por Palácio e Rua da Cadeia a subir a ladeira" "que vai junto ao seminário de São José até se recolher na antiga catedral", ${ }^{25}$ no Morro do Castelo, prática essa realizada até o século XIX.

\section{O arrematador José Antônio de Freitas Guimarães.}

Os arrematadores das festas forneciam artigos para as procissões e missas como fogos de artifício, armações para o pálio ou para palanques, tablados, arcos triunfais, pagamento dos músicos para os cortejos e celebrações nas Sés, nova e antiga, cuidados com a imagem e andor de São Sebastião e principalmente cera de vela para as luminárias, ${ }^{26}$ para as propinas pagas aos oficiais da Câmara, aos membros da justiça e principais cargos políticos, para o comparecimento nas festas, ${ }^{27}$ além do ornamentos na Igreja. Três dias antes do início oficial das festas ao padroeiro já começava "o justo e louvável costume de porem os moradores desta mesma cidade luminárias na noite dos sobreditos dias 17, 18 e 19 do corrente, na forma costumada desde o princípio da fundação desta cidade, com pena de 3\$000". ${ }^{28}$

Assim, as luzes que marcavam as festas davam status aos que pagavam as ceras das velas e aos que recebiam, tanto que, no caso do Rio de Janeiro, as propinas eram pagas em cera. A documentação mostra que por ser o item mais fornecido, claramente, era o que demandava mais gastos. Como já afirmamos, o maior desses arrematadores da festa de São Sebastião foi José Antônio de Freitas Guimarães. O primeiro registro da investidura se deu em 1795, quando em nota informa que "Este nobre Senado the está devendo 930\$600 importe de 52 arrobas e 28 libras de cera que se gastou nas luminárias e festas no dia 20 de janeiro, oitavário e no dia 27 e procissão pelo haver rematado nos paços do concelho e 550 cada libra e porque haver o seu pagamento". ${ }^{29}$

Já em 19 de fevereiro de 1803, o pagamento seria de " $512 \$ 500$, correspondentes a 40 arrobas e uma libra de cera", que ele arrematou a $12 \$ 800$ o preço de cada libra, valor muito alto em relação ao padrão que traçamos para a arrematação de cada libra, que ia de 300 a 512 réis. ${ }^{30}$ No ano seguinte, em 18 de fevereiro de 1804, o volume de cera foi semelhante, 40 arrobas e 20 libras, no total de $611 \$ 335$ a 460\$, mas o destino seria diferente, não para a festa como um todo, mas especificamente para pagar as propinas. Em 1805, José Antônio de Freitas Guimarães apresenta um requerimento pedindo o pagamento de $600 \$ 480$ réis

\footnotetext{
25 Arquivo da Cúria Municipal do Rio de Janeiro (ACMRJ). Pastorais e Editais, 1742-1838, E236, 17 jan. 1793 e 15 jan. 1799.

26 As luminárias eram panelinhas de barros com azeite de mamona e uma ponta de algodão que se acendia ou cascas de laranja com o mesmo azeite e mechas de algodão.

27 No caso de São Sebastião, as propinas eram pagas antes dos festejos e para o comparecimento no dia 20 e 27 de janeiro.

${ }^{28}$ AGCRJ. 16.4.21, Editais do Senado da Câmara, p. 56v-57v, 13 jan. 1798

${ }^{29}$ AGCRJ. 43.4.18, Festividades de São Sebastião 1786-1830, p. 47A; 47B.

${ }^{30}$ A cera da vela era contada por peso, em arrobas (referente a 14,745kg), e cada arroba valia 32 libras.
} 
referentes a 39 arrobas e três libras de cera. ${ }^{31}$

O que observamos é que 15 anos depois do primeiro registro de pedido de pagamento, José Antônio de Freitas Guimarães continua fornecendo cera para as festividades do padroeiro, posto que em 1810 a quantia a ser paga e volume de cera chega ao máximo de $949 \$ 190$ referentes a 54 arrobas, 14 libras e uma quarta.

As três principais fontes documentais de rastreamento os gastos com as festas de São Sebastião eram os arremates e os pedidos de pagamento após a festa e a autorização da Câmara Portanto, unindo essas três etapas, José Antônio de Freitas Guimarães aparece em 1795, 1803, 1804, 1805 e 1810 pedindo pagamento e em 1807, 1808 e 1809 arrematando para fornecer cera de vela para todas as festas. Ainda que não trate só das celebrações do Glorioso Mártir, o que se estabelece é que fornecer produtos para festa não era um hábito sazonal para Freitas Guimarães, mas sim uma constante, uma de suas estratégias sociais.

José Antônio de Freitas Guimarães era homem de negócios, ${ }^{32}$ português, militar e morador na Rua dos Pescadores, no centro da cidade. ${ }^{33} \mathrm{O}$ arrematador era negociante matriculado na praça do Rio de Janeiro "com estabelecimento de casa de negócios desta cidade, na rua da Candelária n²0, tem vários prédios além de ter muitas transações pendentes.", demonstrando um envolvimento com a cidade colonial, mas também nos primeiros momentos do Império, quando em 1824 solicita que o escrivão da Câmara ateste que ele assinou a Constituição, pois precisava ir à Europa por quatro anos resolver seus negócios e "e não deseja perder o título e qualidade de cidadão brasileiro", ${ }^{44}$ deixando, inclusive seus prédios e negócios como garantia.

Assim como o arremate das festas, nem todas as atividades de Feitas Guimarães eram com objetivo de retorno financeiro direto. Capitão, em 1802 solicita ao Conselho Ultramarino a posição, sem remuneração, em uma das baterias da Fortaleza de Santa Cruz, através de seu procurador José Luís Pereira da Costa. ${ }^{35}$ Do mesmo modo, a busca por prestígio também se faz presente na carta patente anexa, que destaca o "dito José Antônio de Freitas Guimarães no posto do capitão de uma das baterias da referida fortaleza e com ele não vencerá soldo algum, mas gozará de todas as honras e privilégios, liberdades, isenções e franquezas que em razão do mesmo". Já o Conde de Resende destaca

Pelo que ordeno a todos os cabos de guerra e oficiais de milícias e justiça, conheçam e hajam ao dito José Antônio de Freitas Guimarães por capitão de uma das ditas baterias, e como o tal honrem, o estimem e os seus subalternos e soldados dela tudo the obedeçam, cumpram e guardem nas ordens por escrito e de palavras como se devem e são obrigados no que se toca o Real Serviço ${ }^{36}$

\footnotetext{
${ }^{31}$ AGCRJ. 43.3.90, Festividades de São Sebastião, requerimento de José Antônio de Freiras Guimarães, 1805.

32 AHU. ACL, CU 017, cx. 202, doc. 14296. 11 ago. 1802.

33 Almanaque do Rio de Janeiro. Revista do Instituto Histórico e Geográfico Brasileiro, Rio de Janeiro, t. 267, abr.-jun. 1965, p. 269.

34 Biblioteca Nacional - Rio de Janeiro (BN-RJ). C0446, 35 N. 001.

${ }^{35} \mathrm{AHU} . \mathrm{ACL}, \mathrm{CU} 017$, cx. 1.98, doc. 14052. Rio de Janeiro, 19 jan. 1802.

${ }^{36}$ Idem.
} 
Por ser comerciante de grosso trato, conseguimos entender de onde vinha as rendas que possibilitavam o empréstimo ao Senado da Câmara e solicitação de baterias, para a ampliação da sua gama de possibilidades de prestígio, sem necessariamente receber soldo por isso, ${ }^{37}$ as práticas de troca iam além da moeda, perpassavam pela economia simbólica.

A prática da administração por arremates de Feitas Guimarães, ainda por vários anos, nem sempre foi sem reclamações da demora do pagamento. O primeiro caso é em 23 de abril de 1797, quando o arrematador alega que há dois anos assistiu "a este nobilíssimo Senado com toda a cera para as festividades e propinas" e que este estava Ihe devendo a quantia de $807 \$ 520$, e é "o suplicante um pobre que não pode sofrer com considerável quebra do seu comércio, um tão grande impacto e demora" ${ }^{38}$ e por isso, recorre a piedade dos camarários. Apesar de se auto intitular pobre, forneceu uma alta quantia de cera e propinas, e mesmo assim não parou de assistir o Senado nos anos subsequentes, mesmo que o pagamento total desta dívida só fosse finalizado em 1799 , ou seja, 4 anos depois. ${ }^{39}$

Portanto, apesar de mais raros, os pagamentos poderiam atrasar, mesmo que para o caso do Rio de Janeiro não ter sido registrado reclamações da ouvidoria ou para o Conselho Ultramarino dos altos gastos do Senado da Câmara com as festividades, ao contrário do que relatado, por exemplo, para Vila Rica. ${ }^{40} \mathrm{Em} 11$ de abril de 1804, a abordagem de José Antônio de Freitas Guimarães muda para solicitar o que faltava, o valor de $311 \$ 355$, do pagamento da festa de São Sebastião daquele ano e explicava que "precisa o suplicante haver o seu pagamento, para continuar com as ceras que ainda precisam este nobre Senado, e do contrário, não se pode fazer por ser esse gênero de grande falta". Abordando ainda o notório custo que ele tem com a atividade, Freitas Guimarães marca como sua ação com a Câmara era importante para a própria instituição, tanto por fornecer as ceras, como ter réis para tal. A querela não demora a se resolver e em 18 dias é autorizado o pagamento. ${ }^{41}$

As estratégias na sociedade de Antigo Regime eram variadas, dependendo dos grupos e seus objetivos. Nesse sentido a antropologia auxilia a entender que mesmo que participando da mesma cultura, há diferenças fundamentais que a distingue internamente. Fredrik Barth, ao estudar as fronteiras étnicas dentro das próprias culturas, analisa que as sociedades são abertas e fragmentada, ainda que altamente hierarquizadas em razão dos atores sociais envolvidos, posto que as ações destes resultam de escolhas e estratégias próprias, o que confere uma certa tensão e neste sentido, incerteza ou imprevisibilidade. ${ }^{42}$ Barth percebe em Sohar que a demanda social se dá pela imposição do poder a partir do entendimento das

\footnotetext{
37 Almanaque do Rio de Janeiro. Revista do Instituto Histórico e Geográfico Brasileiro, Op. cit. , p. 269.

${ }^{38}$ AGCRJ. 43.4.16, Festividades religiosas- requerimento contas e outros processos 1760-1828, p. 34

${ }^{39}$ AGCRJ. 43.4.16, Festividades religiosas- requerimento contas e outros processos 17601828 , p. 45.

40 SANTIAGO, Camila Fernanda Guimarães. A Vila em ricas festas: celebrações promovias pela Câmara de Vila Rica. Belo Horizonte: C/ Arte; FACE-FUMEC, 2003.

${ }^{41}$ AGCRJ. 16.1.5, Festas do Senado da Câmara 1786-1830.

42 BARTH, Fredrik. Process and forms in social life. Vol. I. London: Routlegde \& Kegan Paul, 1981.
} 
diferenças dos grupos. Assim, pequenas diferenças são construídas dentro dos limites das ações, que, uma vez estabelecidos, podem-se construir a noção de sociedade. ${ }^{43}$

Deste modo, a ação dos arrematantes não é aleatória, tem um que de caos, e também de orientação valorativa, ${ }^{44}$ dentro do norte que é a cultura política de poder e prestígio da sociedade aqui estudada. Parte das opções e estratégias vêm dos valores que os atores dispõem, e no caso de Freitas Guimarães, sua carreira militar, seus negócios e suas relações com o Senado da Câmara. Importante destacar que esses valores têm ligação com o meio social e da disposição que ele tinha de usar seus recursos próprios para criar com suas parentelas e seus aliados, mesmo sem soldo alto de retorno, o que não era possível para todas as camadas da sociedade colonial, por isso evidenciamos que Freitas Guimarães e seus arrematadores faziam parte de uma elite que dispunha condições de emprestar réis a administração colonial.

O que observamos é que, para além dos soldos, era importante que José Antônio de Freitas Guimarães se mantivesse e até ampliasse e seu espectro de serviços à Coroa. Além da festa de São Sebastião, ele arrematou todas as festas para o período em que manteve sua atividade, chegando a gastar o impressionante montante de "1:292\$690, correspondentes ao fornecimento que fez de 68 arrobas e 15 libras de cera para as festividades em regozijo ao feliz nascimento do Príncipe D. Antônio, em 1795". ${ }^{45}$ Freitas Guimarães também pagou pelas propinas das festas de São Sebastião nos anos de 1804 e 1810, gastando respectivamente $611 \$ 335$ (40 arrobas e 20 libras de cera, a 460\$ cada libra) e $949 \$ 190$ (53 arrobas, 14 libras e 1 quarta de cera, a 555\$ cada libra). Os valores despendidos às festas oficiais no Rio de Janeiro devem ser destacados, Nireu Cavalcanti aponta que com cerca de $807 \$ 500$ já era possível comprar uma boa casa térrea na cidade ${ }^{46}$ mostrando, assim, que para praticar o hábito de emprestar ao Senado uma quantia tão alta, deveria ser um indivíduo que possuísse um montante suficiente para estar disponível para despender com as festas e aguardar meses do seu pagamento.

\section{Considerações finais}

Uma das questões que fica mais latentes na pesquisa é o "por que fornecer itens para a festa?", se não há um retorno econômico claro. A contemporaneidade do capitalismo logo nos remete a resposta rápida da atuação somente pelo lucro ou mesmo ao monopólio das vendas, como no caso dos arremates dos açougues e talhos, posto que o que era cobrado pelos arrematadores das festas eram o mesmo que foi gasto, sem porcentagem de juros, ou com

\footnotetext{
${ }^{43}$ BARTH, Fredrik. Sohar, Culture and Society in an Oman Town. Baltimore: Johns Hopkins University Press, 1983.

${ }^{44}$ BARTH, Fredrik. O guru, o iniciador e outras variações antropológicas. Rio de Janeiro: Contra-Capa, 2000 , p. 27.

${ }^{45}$ AGCRJ. 43.4.17, Festividades religiosas do Senado da Câmara - requerimento, contas etc. 1783-1822, p. 6

${ }^{46}$ CAVALCANTI, Nireu. O Rio de Janeiro setecentista... Op. cit., p. 324.
} 
margem de lucro ínfimos se comparado a monopólio de comercialização. Então, porque investir nessa atividade? Ou melhor, porque emprestar ao Senado, e não gastar em algo que aumentasse seu cabedal? Além disso, do ponto de vista religioso, o questionamento se deu que se fosse apenas um ato devocional, não haveria a cobrança das investidas, o se sentir "mais devoto", porque realizou a festa, deveria bastar. No entanto, não bastava separar os usos econômicos dos simbólicos ou dos políticos (a estratégia de ser uma porta de entrada para o Senado, por exemplo).

Do ponto de vista administrativo, a historiografia vem trabalhando a utilização das festas oficiais como espaço de reafirmar tanto o poder régio, como observador nos altos gastos em luxo e ostentações da festa barroca, como no aspecto local, pela administração das Câmaras municipais. Fernanda Fioravante ao analisar as Câmaras mineiras coloniais explica que

Constituindo-se em mecanismos institucionais, as festas integravam o processo de dominação e aumento do poder régio nos Estados Modernos. Além de uma melhor definição das fronteiras, de um aprimoramento do aparato militar e de uma maior organização administrativa, fazia-se necessário, também, publicizar a imagem do rei. ${ }^{47}$

Já na perspectiva local, os trabalhos versam sobre as prestações de serviços das Câmaras municipais, como espaço de exporem como eram "fiéis vassalos" e solicitarem mercês ao rei/rainha, por meio do organização geral das festas, ou são estudos mostrando o funcionamento interno das contas públicas (e o espaço que as festas ocupam nas despesas), ou até mesmo abordando a Câmara como espaço de manutenção ou enriquecimento dos homens bons. Portanto, podemos destacar alguns trabalhos como de Fioravante, de Lívia Monteiro para a Câmara de São João del Rei, Camila Santiago para Vila Rica, Ediana Mendes para Salvador e das pesquisas de Mary Del Priori e Beatriz Catão Santos para a América Portuguesa. ${ }^{48}$

Neste sentido, percebemos esferas de poder em torno do sagrado e na utilização disso para garantir a legitimidade social, fosse pela instituição monárquica, pela instituição de poder local, ou, como é ponto focal desta pesquisa, pelos os atores sociais que ainda de forma "satélite" merecem ser evidenciados nessa lógica, posto que tentavam participar da estratificação social do que chamamos de economia das festas oficiais. Nossa hipótese é que ter um volume suficiente alto para prover serviços e produtos era uma forma de tentar marcar sua posição social e se inserir na hierarquia que a própria sociedade de Antigo Regime criava. Afinal, para além das estratégias individuais, a sociedade estudada que se baseava em torno

\footnotetext{
47 FIORAVANTE, Fernanda. O poder das festas: as festividades barrocas e o poder nas Minas no século XVIII. Instrumento - Revista de Estudos e Pesquisas em Educação, v. 10, 2009, p. 63.

48 Respectivamente: MONTEIRO, Lívia Nascimento. Administrando o bem comum: Homens bons e a câmara de São João del Rei 1730-1760. 2010. Dissertação (Mestrado em História Social) - Programa de Pós-graduação em História Social da Universidade Federal do Rio de Janeiro, Rio de Janeiro; SANTIAGO, Camila Fernanda Guimarães. A Vila em ricas... Op. cit. MENDES, Ediana Ferreira. Festas e procissões reais na Bahia colonial. 2011. Dissertação (Mestrado em História Social) - Universidade Federal da Bahia, Salvador. DEL PRIORE, Mary Lucy. Festas e Utopias no Brasil Colonial. São Paulo: Brasiliense, 2000. SANTOS, Beatriz Catão Cruz. O Corpo de Deus... Op. cit.
} 
de mercês, cargos, terras e, novamente, honra e prestígio, não permitia que a representação fosse apenas pelo viés simbólico cultural ou pelo viés econômico, a "teatralização" causava a impossibilidade dessa separação dos signos.

Desta forma, se os atores sociais forjavam o mundo social em ritos, comportamentos, cerimônias e atos públicos era porque a sociedade e cultura colocava regras e concepções como sistemas mais amplos. O prestígio social na sociedade colonial vinha essencialmente do que o ator social representava de si e colocava no âmbito público, o que Nobert Elias chama atenção para como a opinião do outro definia a distinção de cada homem na Sociedade de Corte $^{49}$ era o meio que ele usasse todos os caminhos que estivessem a seu alcance. Neste sentido, não havia melhor lugar do que entrelaçar a religiosidade, fundamental na lógica colonial, agradar ao Senado da Câmara e pedir benesses ao rei, do que arrematando e atuando diretamente num locus social importante, como as festas oficiais e, neste caso, ao padroeiro da cidade de São Sebastião do Rio de Janeiro.

${ }^{49}$ ELIAS, Norbert. A sociedade de corte: investigação sobre a sociologia da realeza e da aristocracia de corte. Rio de Janeiro: Zahar, 2001. 